\title{
Microstructure Evolution During Hot Deformation of REX734 Austenitic Stainless Steel
}

\author{
MYKOLA KULAKOV, JIANGLIN HUANG, MICHAIL NTOVAS, \\ and SHANMUKHA MOTURU
}

\begin{abstract}
Mechanical properties of a REX734 austenitic stainless steel were examined through compression testing over a wide range of temperatures $\left(1173 \mathrm{~K}\right.$ to $1373 \mathrm{~K}\left(900{ }^{\circ} \mathrm{C}\right.$ to $\left.1100^{\circ} \mathrm{C}\right)$ ) and strain rates $\left(0.1\right.$ to $\left.40 \mathrm{~s}^{-1}\right)$ that cover deformation conditions encountered in different metalworking processes. The evolution of microstructure was studied using electron microscopy combined with electron backscatter diffraction and energy-dispersive spectroscopy. Partially recrystallized microstructures were obtained after compression testing at $1173 \mathrm{~K}$ $\left(900{ }^{\circ} \mathrm{C}\right)$, while after deformation at $1273 \mathrm{~K}$ and $1373 \mathrm{~K}\left(1000{ }^{\circ} \mathrm{C}\right.$ and $\left.1100{ }^{\circ} \mathrm{C}\right)$, the material was fully recrystallized almost in all examined cases. The role of dynamic and metadynamic restoration processes in the formation of final microstructure was investigated. $\Sigma 3$ twin boundaries lost their twin character and transformed into general high-angle grain boundaries as a result of deformation, while during recrystallization new $\Sigma 3$ twin boundaries formed. The evolution of precipitates during compression testing and their role in the recrystallization process was also discussed.
\end{abstract}

https://doi.org/10.1007/s11661-019-05558-6

(C) The Author(s) 2019

\section{INTRODUCTION}

Austenitic stainless steels are widely used to manufacture orthopedic implants. ${ }^{[1,2]}$ In the early 1980 s, REX734 nitrogen- and niobium-bearing stainless steel was introduced for the fabrication of femoral prosthesis for a total hip replacement; this alloy is still one of the most common materials used for the fabrication of femoral stems. ${ }^{[3,4]}$ REX 734 stainless steel for femoral stems is marketed under several brand names by different manufacturers and is standardized by both ISO (5832-9) and ASTM (F1586) standards. The addition of nitrogen in REX734 stabilizes austenite, improves resistance to crevice and pitting corrosion, as well as strength during both monotonic and cyclic loading. Compared to another austenitic stainless steel grade $316 \mathrm{~L}$ commonly used in implants, REX 734 provides superior corrosion resistance and mechanical properties. $^{[1,2]}$

Failures of femoral stems made of REX 734 stainless steel are quite rare. ${ }^{[3-6]}$ In some of the documented cases, femoral stems failed after as little as 6 months. ${ }^{[3]}$ The

MYKOLA KULAKOV, JIANGLIN HUANG, MICHAIL NTOVAS, and SHANMUKHA MOTURU are with the Advanced Forming Research Centre, University of Strathclyde, 85 Inchinnan Drive, Renfrew PA4 9LJ, United Kingdom. Contact e-mail: nkulako@gmail.com

Manuscript submitted March 1, 2019.

Article published online December 4, 2019 root cause of these failures is typically associated with the loss of proximal support, improper design, sizing or positioning; once these precursors for failure are met, femoral stems fail through corrosion-initiated fatigue $^{[3,5,7]} \mathrm{A}$ larger grain size and lower hardness are also often noted on the surface compared to the stem interior; the heterogeneity of grain structure was suggested as one of the factors contributing to fatigue failures. ${ }^{[3,5]}$ Coarse and brittle second phase particles act as preferential sites for the initiation of fatigue cracks during cyclic loading. ${ }^{[8]}$ Fatigue cracks can also initiate at $\Sigma 3$ annealing twin boundaries in austenitic stainless steels. ${ }^{[9,10]}$

The above observations of microstructure deficiencies that potentially contribute to femoral stem failures suggest the need to carefully control microstructure evolution during REX 734 hot forming. Several studies reported various aspects of the hot deformation behavior for a REX 734 alloy. The material behavior after solution annealing at $1523 \mathrm{~K}\left(1250{ }^{\circ} \mathrm{C}\right)$ for 600 seconds was studied through hot torsion testing at strain rates 0.01 to $10 \mathrm{~s}^{-1}$ and temperatures $1173 \mathrm{~K}$ to $1473 \mathrm{~K}$ $\left(900{ }^{\circ} \mathrm{C}\right.$ to $\left.1200{ }^{\circ} \mathrm{C}\right) \cdot{ }^{[11,12]}$ According to the processing map, deformation temperature should be above about $1323\left(1050{ }^{\circ} \mathrm{C}\right)$ to avoid flow instabilities; in this temperature range, microstructure evolution is dominated by dynamic recrystallization. Hot torsion simulations of a multipass deformation process after solutionizing heat treatment at $1523 \mathrm{~K}\left(1250{ }^{\circ} \mathrm{C}\right)$ for 300 seconds during continuous cooling showed that the highest non-recrystallization temperature of about 
$1398 \mathrm{~K}\left(1125^{\circ} \mathrm{C}\right)$ was achieved with an interpass time of 30 seconds. ${ }^{[13]}$ The changes in non-recrystallization temperature with interpass time were attributed to the interaction between the recrystallization process and precipitation of tetragonal CrNbN Z-phase ${ }^{[14]}$; shorter interpass times lead to incomplete precipitation, while precipitates coarsen during longer interpass times. Multipass deformation above the non-recrystallization temperature with a short interpass time results in a microstructure comprised of fine grain grains and a distribution of fine precipitates ${ }^{[15,16]}$; fine intragranular Z-phase precipitate increase strength. ${ }^{[17]}$ Grain boundary character distribution may also need to be controlled to optimize the material performance.

In the present study, a series of hot compression tests covering a wide range of temperatures and strain rates was conducted followed by microstructure analysis. Unlike the previous studies ${ }^{[1,12,15]}$ where material was solution annealed prior to mechanical testing, flow properties were evaluated at several temperatures below the solution annealing temperature to avoid coarsening of microstructure. Microstructure after hot compression testing was analyzed using electron microscopy to provide a comprehensive picture of various phenomena taking place under different hot deformation conditions.

\section{MATERIALS AND METHODS}

The REX734 stainless steel employed in this study was produced through air melting followed by electro-slag remelting; the resulting chemical composition is shown in Table I as per the manufacturer's certificate. The material was supplied in the form of a Ø50-mm-round bar in an annealed condition (1800s at $1223 \mathrm{~K}\left(950^{\circ} \mathrm{C}\right)$ followed by water quenching). The composition and properties conformed to ASTM F1586:13 and ISO 5832-9:2007 standards.

$\varnothing 12 \times 18 \mathrm{~mm}$ samples with the axial direction parallel to the radial direction of the as-received round bar were machined for hot compression testing. The tests were conducted at three temperatures - $1173 \mathrm{~K}, 1273 \mathrm{~K}$, and $1373 \mathrm{~K}\left(900{ }^{\circ} \mathrm{C}, 1000{ }^{\circ} \mathrm{C}\right.$, and $\left.1100{ }^{\circ} \mathrm{C}\right)$ and four strain rates $-0.1,1,10$, and $40 \mathrm{~s}^{-1}$ to the average true strain of $\sim 0.6$. For 0.1 and $1 \mathrm{~s}^{-1}$ tests, screw-driven Zwick Z150 and hydraulic Zwick HA250 test machines were employed, respectively; both machines were equipped with three-zone Eurotherm electric furnaces. Samples were coated with glass for lubrication and to protect the surface from gaseous contamination. High strain rate tests at 10 and $40 \mathrm{~s}^{-1}$ were carried out on a Phoenix servo-hydraulic forging simulator equipped with an

Table I. Chemical Composition of REX734 Stainless Steel (Weight Percent)

\begin{tabular}{lcccccr}
\hline $\mathrm{C}$ & $\mathrm{Cr}$ & $\mathrm{Ni}$ & $\mathrm{Mn}$ & Mo & $\mathrm{N}$ \\
\hline 0.036 & 20.90 & 10.39 & 3.72 & 2.18 & 0.43 \\
\hline $\mathrm{Si}$ & $\mathrm{Nb}$ & $\mathrm{Cu}$ & $\mathrm{P}$ & $\mathrm{S}$ & $\mathrm{V}+\mathrm{W}+\mathrm{Co}+\mathrm{Ti}+\mathrm{Al}$ \\
\hline 0.36 & 0.35 & 0.13 & 0.016 & 0.0003 & 0.20 & \\
\hline
\end{tabular}

induction heating system. ${ }^{[18]}$ For all strain rates, a suspension of boron nitride was applied onto the top and bottom faces of each sample and platens to minimize friction. All deformed samples were waterquenched with a delay of about 5 seconds. Stress-strain curves were corrected for compliance, friction, and adiabatic heating. The temperature increase due to deformation heating was calculated assuming that all of the mechanical energy was converted into heat. The highest estimated temperature increase during compression testing at $40 \mathrm{~s}^{-1}$ strain rate was $35 \mathrm{~K}, 25 \mathrm{~K}$, and $19 \mathrm{~K}$ for $1173 \mathrm{~K}, 1273 \mathrm{~K}$, and $1373 \mathrm{~K}\left(900{ }^{\circ} \mathrm{C}, 1000{ }^{\circ} \mathrm{C}\right.$, and $1100{ }^{\circ} \mathrm{C}$ ) test temperatures, respectively; the temperature increase during testing for the rest of strain rates was lower.

The deformed samples were sectioned in the normal-radial direction plane for a detailed microstructure analysis. They were hot-mounted in a conductive epoxy, ground and polished with the last polishing step being carried out on a vibratory polisher with colloidal silica. The samples were examined using a FEI Quanta 650 field-emission gun scanning electron microscope (SEM) equipped with a X-Max ${ }^{\mathrm{N}} 150$ energy-dispersive X-ray spectroscopy (EDS) and NordlysMax ${ }^{3}$ electron backscatter diffraction (EBSD) detectors. Qualitative EDS chemical composition analysis of precipitates was carried out at $10 \mathrm{kV}$ accelerating voltage to minimize the interaction volume. All EBSD scans were conducted using $20 \mathrm{kV}$ accelerating voltage at a step size of $0.3 \mu \mathrm{m}$. The physical EBSD resolution reported for a field-emission scanning electron microscope operated at $15 \mathrm{kV}$ using an iron sample is $30 \mathrm{~nm}$ parallel to the tilt axis and $90 \mathrm{~nm}$ perpendicular to the tilt axis ${ }^{[19]}$; therefore, the selected step size of $0.3 \mu \mathrm{m}$ is likely to be not much greater than the physical resolution at a higher accelerating voltage of $20 \mathrm{kV}$. Approximately $150 \times 200 \mu \mathrm{m}$ areas were scanned at the equatorial mid-radius locations to avoid regions of potentially high strain in the centrer of a sample and low strain near the sample periphery as a moderate barreling was observed for all samples. The indexing rate was over 84 pct and in many cases exceeded 95 pct. The EBSD data were analyzed using MTEX toolbox for Matlab. ${ }^{[20]}$ Grains were detected using the minimum boundary misorientation of $5 \mathrm{deg}$. Grains which comprised less than ten data points were removed. Non-indexed pixels and data points belonging to the fine discarded grains were automatically assigned to neighboring grains. Grain boundaries were also smoothed (Laplacian smoothing, three iterations) to minimize the effect of the pixilated boundary shape obtained with a grid-based EBSD scan on the analysis. For the recrystallization analysis, a grain orientation spread (GOS) of $1.5 \mathrm{deg}$ was used to differentiate recrystallized and unrecrystallized grains. ${ }^{[21]}$ A recrystallized fraction was calculated as a ratio of the area of recrystallized grains to the total scan area. For the grain boundary analysis, boundaries with a misorientation between 5 and $15 \mathrm{deg}$ were considered as low-angle grain boundaries. High-angle grain boundaries were further classified into $\Sigma 3(60 \mathrm{deg}\langle 111\rangle), \Sigma 9$ (38.94 deg $\langle 110\rangle), \Sigma 27$ (31.59 deg $\langle 110\rangle$ and $35.43 \mathrm{deg}$ $\langle 210\rangle)$, and random grain boundaries. The maximum 
deviation from the ideal orientation for $\Sigma 3, \Sigma 9$, and $\Sigma 27$ boundaries were $8.66,5$, and $2.89 \mathrm{deg}$, respectively, according to the Brandon criterion. ${ }^{[22]}$ A fraction of $\Sigma 3$, $\Sigma 9$, and $\Sigma 27$ boundaries was calculated as a ratio of the length of $\Sigma 3, \Sigma 9$, or $\Sigma 27$ boundary segments to the total length of all high-angle grain boundary segments. A ratio of the length of $\Sigma 3$ boundaries to the scan area was used to obtain a density of this boundary type. The average of microstructural parameters listed above was calculated for each EBSD map partitioned into four quadrants; the standard deviation was used to estimate the uncertainty of the EBSD analysis. For fully recrystallized microstructures, the average equivalent grain diameter was calculated with and without twin boundaries for each full EBSD map; in this case, grains were detected using a minimum misorientation of $15 \mathrm{deg}$. Partial grains touching the boundary of the scan frame were excluded from the analysis. Vickers hardness was measured for the same locations analyzed with EBSD; sixteen measurements were conducted at $1 \mathrm{kgf}$ load and 15 seconds of dwell time.

\section{RESULTS}

The starting microstructure comprises equiaxed grains, see Figure 1 (the actual scan area is about four times the map in Figure 1). Most grains possess a grain orientation spread of less than $1 \mathrm{deg}$. Varying the grain orientation spread threshold between 1 and 2 deg had a negligible effect on recrystallized fraction for the as-received material and other samples examined in the present study. There are many annealing twins present in the microstructure. Some of the fine annealing twins that can be discerned in Figure 1(a) are not accounted for in the reconstructed grain structure in Figure 1(c) (white pixels arranged in a linear pattern). This did not have a significant effect on results presented herein due to the fact that these fine microstructural features are relatively infrequent. Most of the grain boundaries are of the high-angle type (about 99 pct). $\Sigma 3$ twin boundaries constitute 55 pct of all high-angle grain boundaries, while there were only 3 and 2 pct of $\Sigma 9$ and $\Sigma 27$ boundaries, respectively. A tolerance angle smaller than the Brandon criterion is often used in the literature to differentiate various boundaries; for example, for $\Sigma 3$ boundaries, a tolerance angle as small as $2 \mathrm{deg}$ has been used. ${ }^{[23]}$ In the as-received material, most of $\Sigma 3$ boundaries are found within $1 \mathrm{deg}$ of the ideal orientation. Both the length fraction and density of $\Sigma 3$ boundaries are rather insensitive to the maximum angular deviation varying between 2 and $8.66 \mathrm{deg}$. The density of $\Sigma 3$ boundaries is about $0.2 \mu \mathrm{m}^{-1}$. The average equivalent grain diameter with and without twin boundaries is equal to 6 and $12 \mu \mathrm{m}$, respectively, due to the fact that $\Sigma 3$ twin boundaries constitute 55 pct of the entire length of all high-angle grain boundaries. The hardness of the as-received material is about $240 \mathrm{HV}$. The high-magnification backscatter electron image in Figure 2(a) shows second phase particles in the as-received material. Although quantitative chemical analysis of precipitates in SEM is not possible due to a relatively large
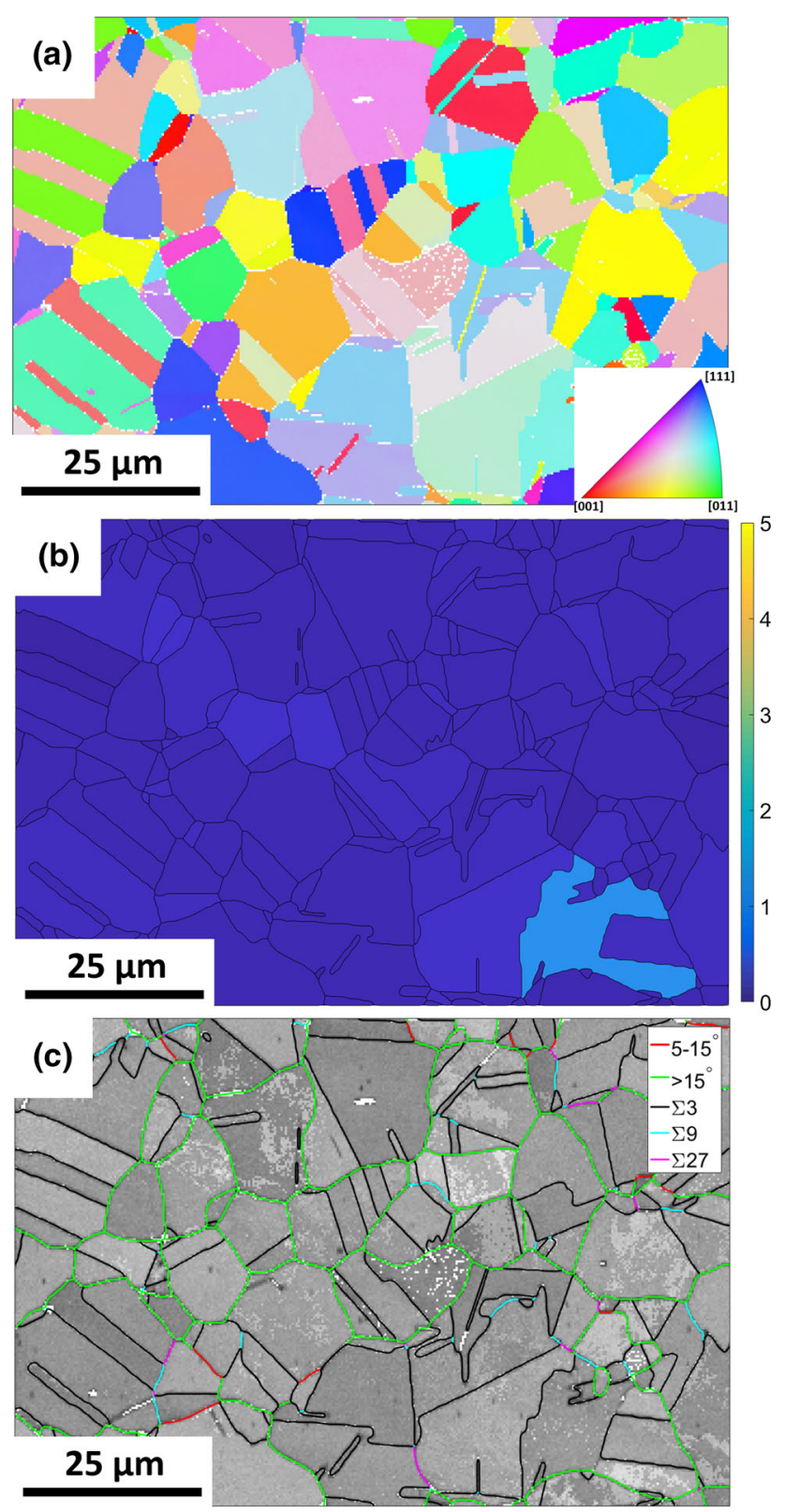

Fig. 1-Microstructure of the as-received REX734 stainless steel: $(a)$ as-collected orientation map (inverse pole figure coloring with respect to the radial direction of the as-received $\varnothing 50 \mathrm{~mm}$ round bar), (b) grain orientation spread map, (c) band contrast map with different types of grain boundaries.

interaction volume even at $10 \mathrm{kV}$ accelerating voltage and unavoidable contributions to the signal from the matrix, chemical composition of the precipitates detected in the as-received material was analyzed qualitatively. The three main peaks for the location far from any visible precipitates (orange diamond in Figure 2(b)) correspond to iron, chromium, and nickel, in agreement with the nominal chemical composition shown in Table I. Three types of second phase particles were identified in the as-received material. The larger elongated and smaller spherical light particles have a similar chemical composition and contain mostly niobium and chromium as shown in Figure 2(b) (red triangle and 

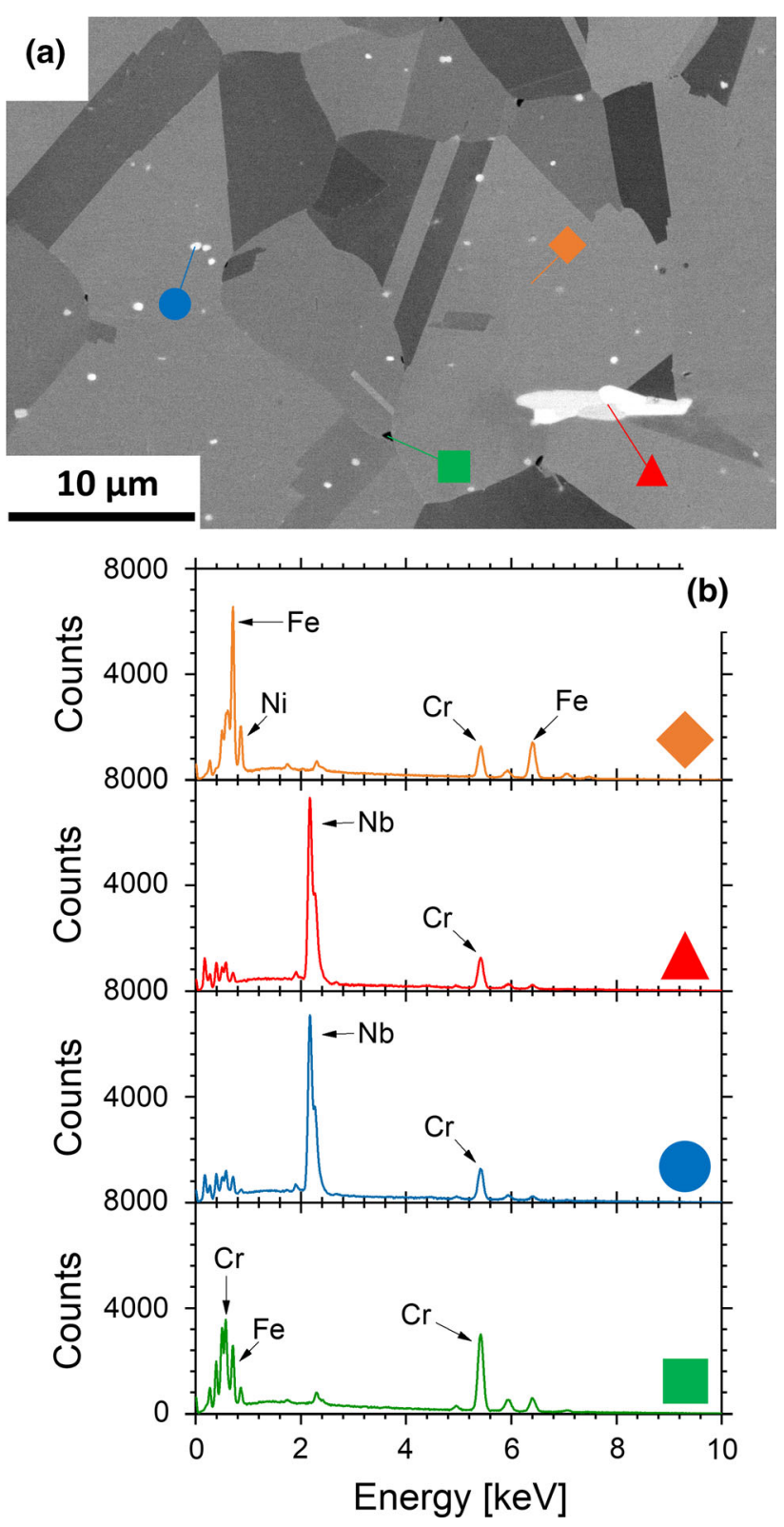

Fig. 2-Microstructure of the as-received REX734 stainless steel: (a) backscattered electron image, $(b)$ EDS spectra of the regions marked in (a).

blue circle); these precipitates are likely to be a tetragonal $\mathrm{CrNbN}$ Z-phase. ${ }^{[14]}$ The large up to about $10-\mu \mathrm{m}$-long Z-phase precipitates are elongated in the rolling direction, while spherical submicron Z-phase particles are found both on grain boundaries and inside of grains. Small dark second phase particles mostly contain chromium; these are likely to be chromium nitrides. ${ }^{[24]}$

The flow stress increases with decreasing temperature and increasing strain rate, see Figure 3 . All of the stress-strain curves exhibit a single peak suggesting the occurrence of dynamic recrystallization ${ }^{[25,26]}$; although the peak is not well defined for the highest strain rate of $40 \mathrm{~s}^{-1}$.

The effect of deformation temperature and strain rate on recrystallized volume fraction is shown in Figure 4.
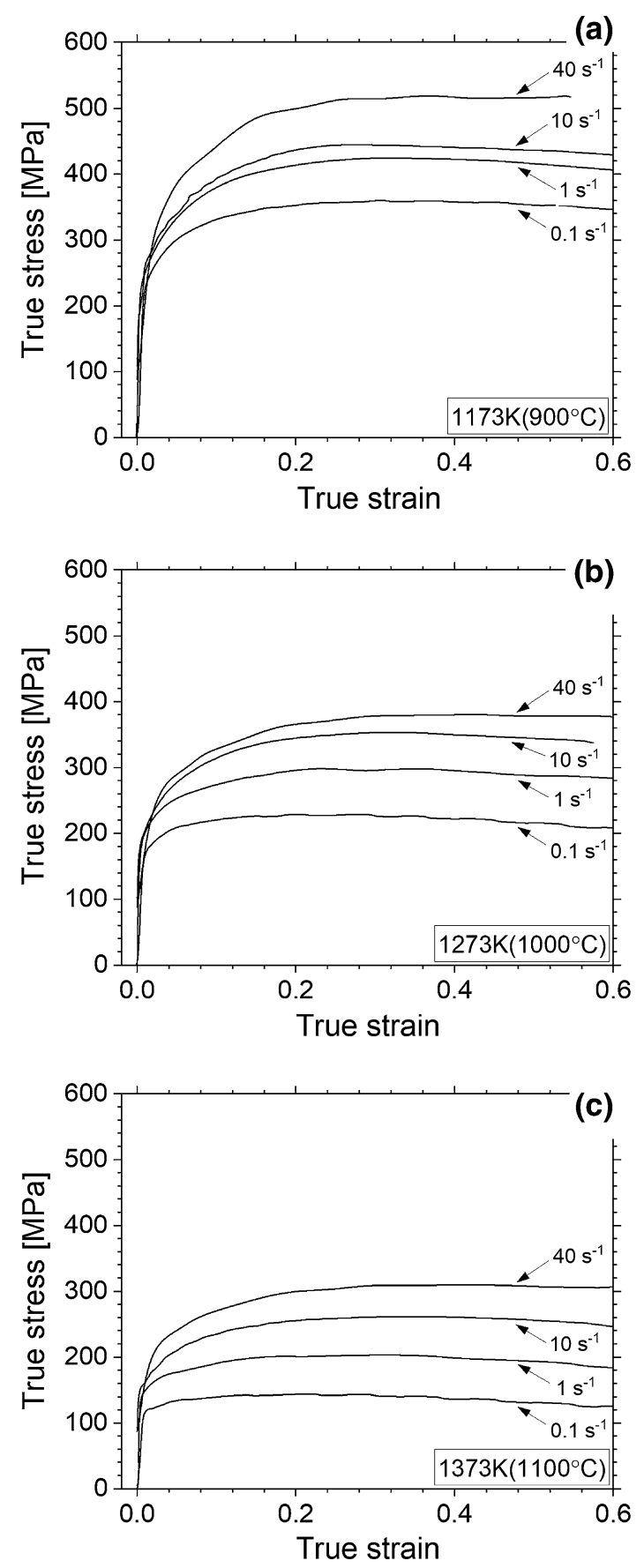

Fig. 3- Stress-strain curves at (a) $1173 \mathrm{~K}\left(900{ }^{\circ} \mathrm{C}\right), \quad(b) \quad 1273 \mathrm{~K}$ $\left(1000{ }^{\circ} \mathrm{C}\right)$, and $(c) 1373 \mathrm{~K}\left(1100{ }^{\circ} \mathrm{C}\right)$.

Higher recrystallized volume fractions are observed at higher temperatures. For $1173 \mathrm{~K}$ and $1273 \mathrm{~K}\left(900{ }^{\circ} \mathrm{C}\right.$ and $1000{ }^{\circ} \mathrm{C}$ ) deformation temperatures, recrystallized volume fraction increases with strain rate.

An example of a partially recrystallized microstructure after deformation at $1173 \mathrm{~K}\left(900{ }^{\circ} \mathrm{C}\right)$ temperature and $40 \mathrm{~s}^{-1}$ strain rate is shown in Figure 5. Recrystallized grains with a much lower GOS compared to elongated unrecrystallized grains are located in the vicinity of boundaries of deformed grains as shown in Figure $5(\mathrm{~b})$. The partitioning to differentiate between 
recrystallized and unrecrystallized grains illustrates that low-angle grain boundaries formed in unrecrystallized grains. Moreover, $\Sigma 3$ twin boundaries that comprise about half of all high-angle grain boundaries in the starting microstructure are virtually absent within deformed grains; only recrystallized grains contain twin

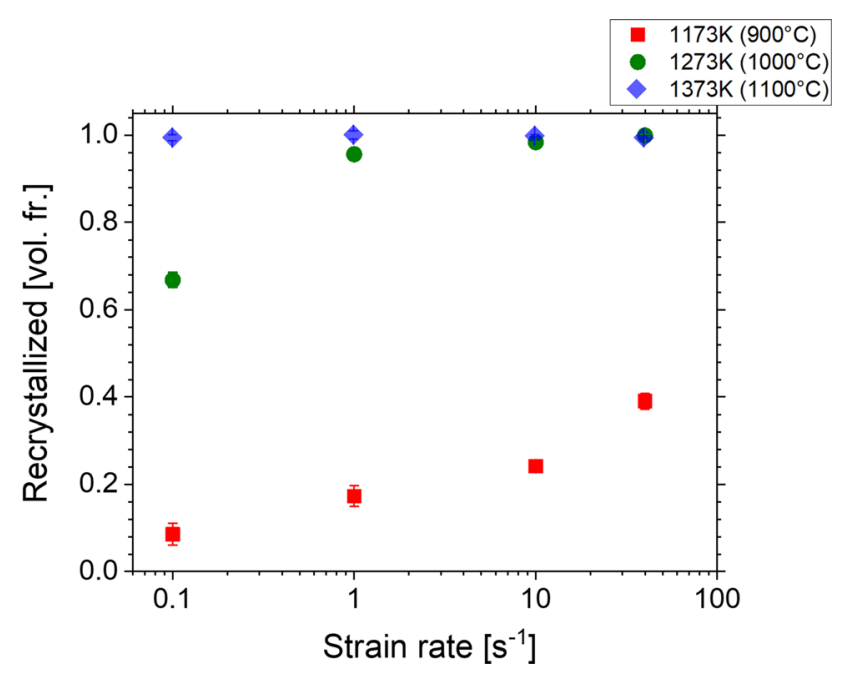

Fig. 4-Effect of deformation temperature and strain rate on recrystallized volume fraction (error bars denote one standard deviation based on the quadrant analysis).
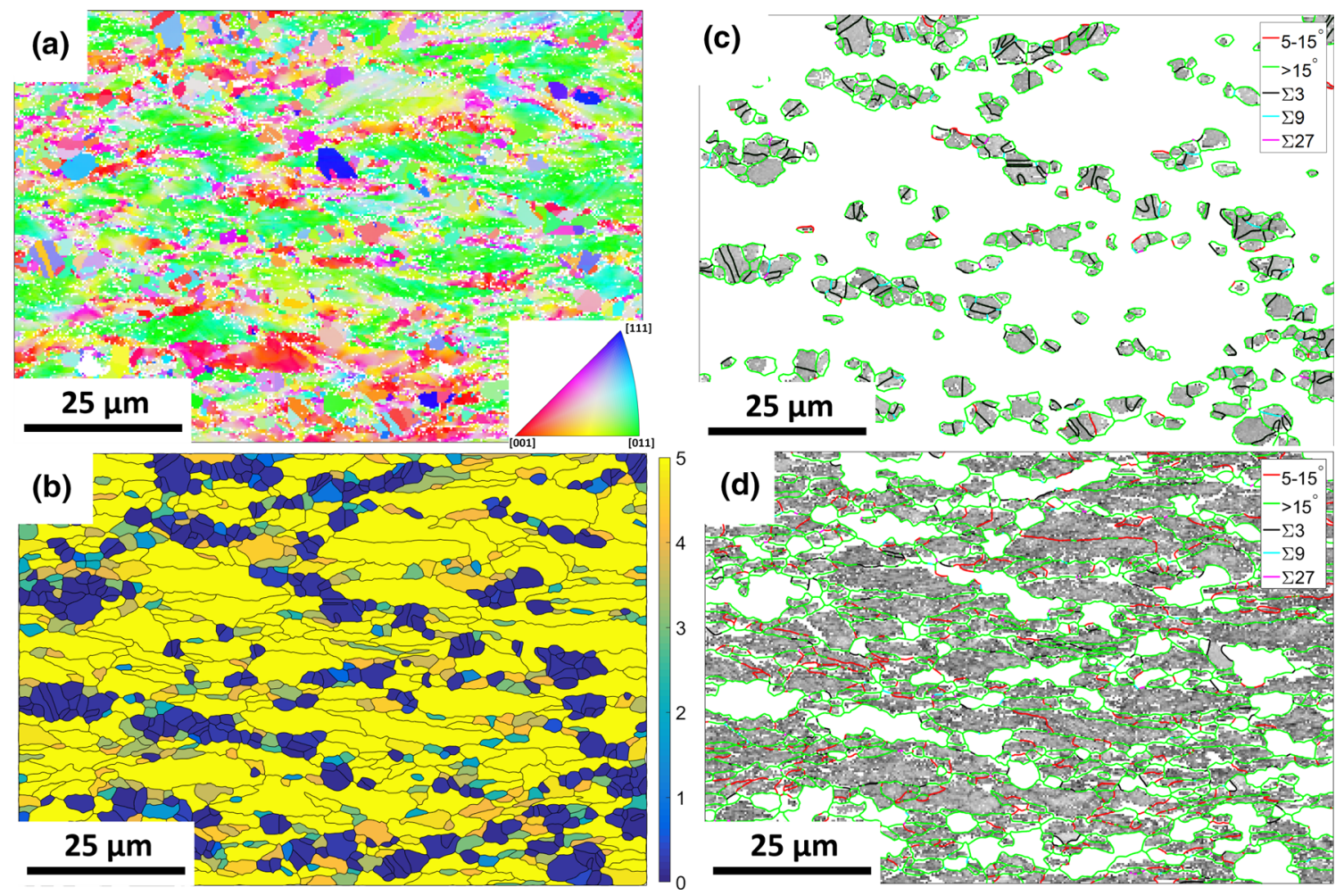

boundaries newly formed in the course of recrystallization, see Figures 5(c) and (d).

A fully recrystallized microstructure after deformation at $1273 \mathrm{~K}\left(1000{ }^{\circ} \mathrm{C}\right)$ temperature and $1 \mathrm{~s}^{-1}$ strain rate comprises fine equiaxed grains, Figure 6 . The majority of the grains possess a low grain orientation spread. Similarly to the starting microstructure, general high-angle grain boundaries and annealing twin boundaries are prevalent after the completion of recrystallization.

For fully recrystallized microstructures, the average grain diameter with $\Sigma 3$ twin boundaries excluded is about twice the grain size when all high-angle grain boundaries are taken into account (Figure 7). Compared to the initial pre-deformation microstructure, the grain size decreases by a factor of two when the material is deformed at $1273 \mathrm{~K}\left(1000{ }^{\circ} \mathrm{C}\right)$; a smaller grain refinement is achieved during deformation at $1373 \mathrm{~K}$ $\left(1100{ }^{\circ} \mathrm{C}\right)$. At $1373 \mathrm{~K}\left(1100{ }^{\circ} \mathrm{C}\right)$ deformation temperature where fully recrystallized microstructure was obtained for the entire strain rate range employed in this study, the grain size decreases as strain rate is increased.

A summary of changes in the population of various grain boundaries for different deformation temperatures and strain rates is shown in Figures 8 through 10. Only in partially recrystallized microstructures (all four strain rates at $1173 \mathrm{~K}\left(900{ }^{\circ} \mathrm{C}\right)$ deformation temperature and $0.1 \mathrm{~s}^{-1}$ at $1273 \mathrm{~K}\left(1000{ }^{\circ} \mathrm{C}\right)$ ), low-angle grain boundaries constitute a significant fraction of all boundaries;

Fig. 5-Partially recrystallized microstructure after deformation at $1173 \mathrm{~K}\left(900{ }^{\circ} \mathrm{C}\right)$ temperature and $40 \mathrm{~s}^{-1}$ strain rate: (a) as-collected orientation map (inverse pole figure coloring with respect to the compression axis), (b) grain orientation spread map, band contrast map with different types of grain boundaries in $(c)$ recrystallized and $(d)$ unrecrystallized grains. 

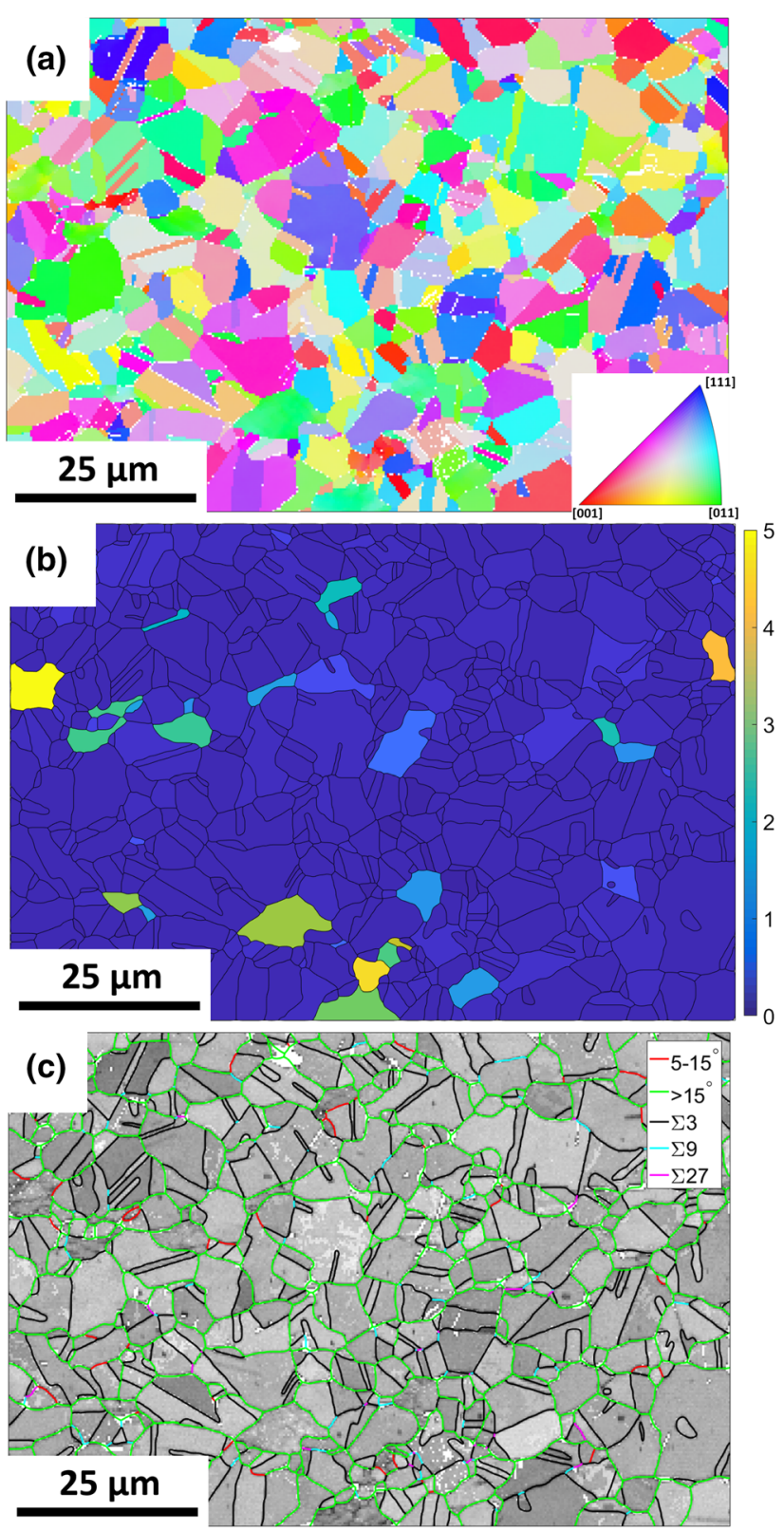

Fig. 6-Fully recrystallized microstructure after deformation at $1273 \mathrm{~K}\left(1000{ }^{\circ} \mathrm{C}\right)$ temperature and $1 \mathrm{~s}^{-1}$ strain rate: $(a)$ as-collected orientation map (inverse pole figure coloring with respect to the compression axis), (b) grain orientation spread map, (c) band contrast map with different types of grain boundaries.

in fully recrystallized samples, low-angle grain boundaries are virtually absent, Figure 8 . At $1173 \mathrm{~K}\left(900^{\circ} \mathrm{C}\right)$ deformation temperature, the fraction of $\Sigma 3$ annealing twin boundaries increases with strain rate and recrystallized fraction, Figures 9(a) and (b). Irrespective of strain rate and/or deformation temperature, in fully recrystallized samples, the fraction of $\Sigma 3$ annealing twin boundaries reaches a constant level of about 0.5 , i.e., similar to the pre-deformation content. The density of $\Sigma 3$ grain boundaries increases with strain rate for all three deformation temperatures; this is correlated to the increase in recrystallized fraction with strain rate after deformation at $1173 \mathrm{~K}\left(900{ }^{\circ} \mathrm{C}\right)$ as well as the decrease
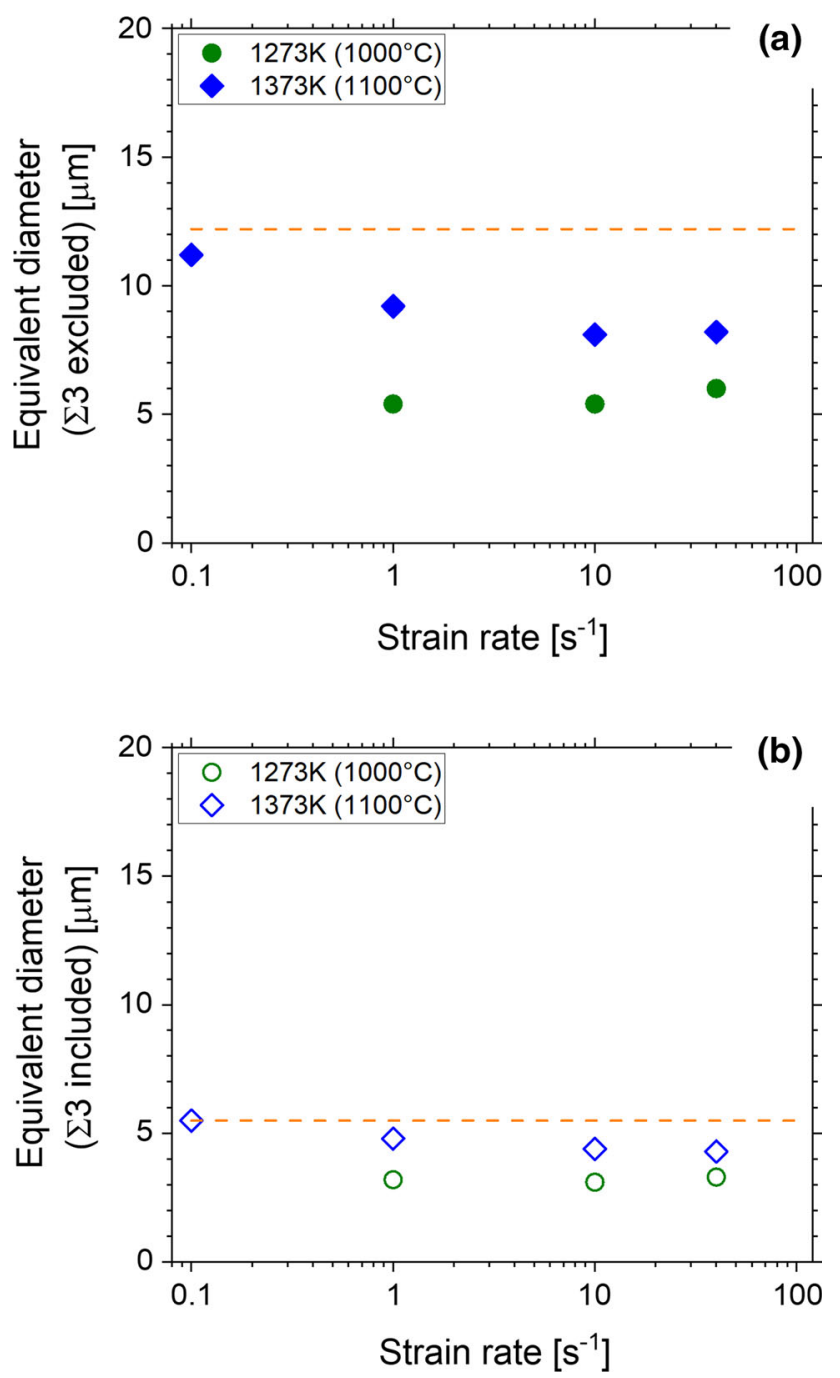

Fig. 7-Grain size analysis in fully recrystallized samples (a) excluding and $(b)$ including annealing twin boundaries (broken lines indicate initial microstructure).

in the average recrystallized grain size in fully recrystallized samples, Figures 9(c) and (d).

Only a relatively small fraction of high-angle grain boundaries fulfill the criteria for $\Sigma 9$ and $\Sigma 27$ boundaries generated through the interaction of $\Sigma 3^{\mathrm{n}}$ boundaries; their cumulative fraction is below about 5 pct and there is no well-defined trend on how the $\Sigma 9$ and $\Sigma 27$ boundary fraction changes with deformation temperature and strain rate, Figure 10.

Microstructure after deformation at the three temperatures and $1 \mathrm{~s}^{-1}$ strain rate is shown in Figure 11. Both large elongated and small spherical Z-phase particles are present in all samples; visually, their volume fraction did not change compared to the pre-deformation microstructure shown in Figure 2. Even the highest deformation temperature of $1373 \mathrm{~K}$ $\left(1100{ }^{\circ} \mathrm{C}\right)$ is still about $150-200 \mathrm{~K}$ below the Z-phase solvus temperature. ${ }^{[16,17,24]}$

Dark precipitates [marked with white arrows in Figure 11(a)] considered to be chromium nitrides delineate some grain boundaries after deformation at $1173 \mathrm{~K}$ 

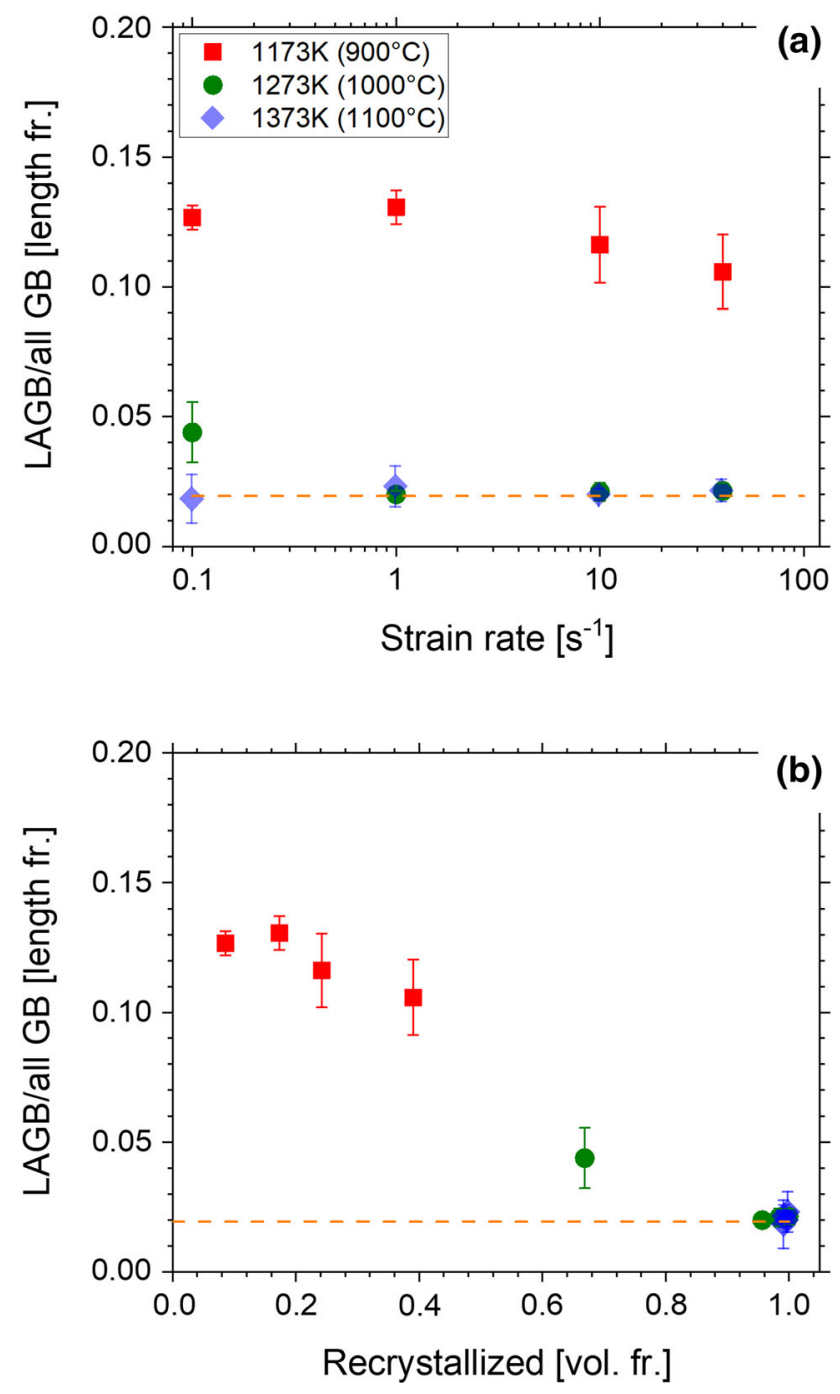

Fig. 8 - Length fraction of low-angle grain boundaries as a function of $(a)$ deformation temperature and strain rate, $(b)$ recrystallized volume fraction (broken lines indicate initial microstructure, error bars denote one standard deviation based on the quadrant analysis).

$\left(900{ }^{\circ} \mathrm{C}\right)$. Qualitatively, there appears to be more precipitates compared to the starting microstructure. The solvus temperature for chromium nitrides is between about $1273 \mathrm{~K}$ and $1343 \mathrm{~K}\left(1000{ }^{\circ} \mathrm{C}\right.$ and $\left.1070{ }^{\circ} \mathrm{C}\right)$ depending on the nitrogen concentration. ${ }^{[24]}$ Additional chromium nitride precipitates formed along boundaries of undeformed grains during the soaking at $1173 \mathrm{~K}$ $\left(900{ }^{\circ} \mathrm{C}\right)$ prior to deformation. Some chromium nitrides are still present in fully recrystallized microstructure after deformation at $1273 \mathrm{~K}\left(1000{ }^{\circ} \mathrm{C}\right)$, Figure $11(\mathrm{~b})$. Most of them are no longer residing on grain boundaries as they detached from grain boundaries in the course of recrystallization. All chromium nitride precipitates dissolved after compression testing above the solvus temperature at $1373 \mathrm{~K}\left(1100^{\circ} \mathrm{C}\right)$, Figure $11(\mathrm{c})$.

Hardness mainly depends on the deformation temperature rather than on strain rate as shown in Figure 12. A significantly higher hardness can be achieved after compression at $1173 \mathrm{~K} \quad\left(900{ }^{\circ} \mathrm{C}\right)$ compared to $1273 \mathrm{~K}$ and $1373 \mathrm{~K} \quad\left(1000^{\circ} \mathrm{C}\right.$ and $\left.1100{ }^{\circ} \mathrm{C}\right)$. However, strain rate has an almost negligible effect on the final hardness.

\section{DISCUSSION}

Compared to high-temperature mechanical properties reported for a REX734 austenitic stainless steel [1 and $10 \mathrm{~s}^{-1}$ at $1173 \mathrm{~K}, 1273 \mathrm{~K}$, and $1373 \mathrm{~K}\left(900{ }^{\circ} \mathrm{C}\right.$, $1000{ }^{\circ} \mathrm{C}$, and $\left.\left.1100^{\circ} \mathrm{C}\right)\right],{ }^{[11]}$ flow stress values obtained in this study are about 20 pct higher. The material in the previous study was solutionized for 600 seconds at $1523 \mathrm{~K}\left(1250{ }^{\circ} \mathrm{C}\right)$ and had a grain size of $85 \mu \mathrm{m}$ before deformation; moreover, the time during cooling at $2 \mathrm{~K} \mathrm{~s}^{-1}$ to deformation temperatures and during torsion testing might not have been sufficient to re-precipitate all second phase particles. For example, it takes more than 600 seconds to reach peak hardness due to precipitation of Z-phase during aging of REX734 at $1273 \mathrm{~K}$ $\left(1000{ }^{\circ} \mathrm{C}\right) \cdot{ }^{[17]}$ While in the present study, the material was deformed without solutionizing and had a relatively small grain size of $12 \mu \mathrm{m}$. These microstructural differences explain the higher flow stresses observed in the present study.

As the stress-strain curves shown in Figure 3 exhibit peaks, dynamic recrystallization started during compression testing. Typically, an increase in strain rate delays dynamic recrystallization. ${ }^{[26]}$ However, the observed increase in recrystallized volume fraction with strain rate suggests that metadynamic recrystallization took place during the quench delay. Even at the lowest strain rate of $0.1 \mathrm{~s}^{-1}$, it took 6 seconds to achieve the final strain of 0.6 followed by 5 seconds of delay before quenching; for higher strain rates, the quench delay is orders of magnitude higher than the deformation time. Recrystallized grains formed during deformation most likely grew rapidly during the few seconds available after deformation prior to quenching. An increase in strain rate also accelerates metadynamic recrystallization $^{[27]}$ by suppressing dynamic recovery so that a higher stored energy is available for metadynamic recrystallization. Finally, as most of the mechanical energy is dissipated in the form of heat during deformation, adiabatic heating also contributes to the acceleration of recrystallization kinetics with strain rate; the temperature increase due to deformation heating is higher at low deformation temperatures as discussed above. The absence of a significant intragranular misorientation after the completion of recrystallization (see Figure 6) also supports the above conclusion that most of recrystallization took place during the quench delay. Partially recrystallized samples after deformation at $1173 \mathrm{~K}\left(900{ }^{\circ} \mathrm{C}\right)$ possess a significantly higher hardness compared to samples deformed at either $1273 \mathrm{~K}$ or $1373 \mathrm{~K}\left(1000{ }^{\circ} \mathrm{C}\right.$ or $\left.1100{ }^{\circ} \mathrm{C}\right)$. However, the stressstrain curves shown in Figure 3 suggest a limited extent of softening and, therefore, of dynamic recrystallization during deformation. This observation once again suggests that most of recrystallization happened during the quench delay. 

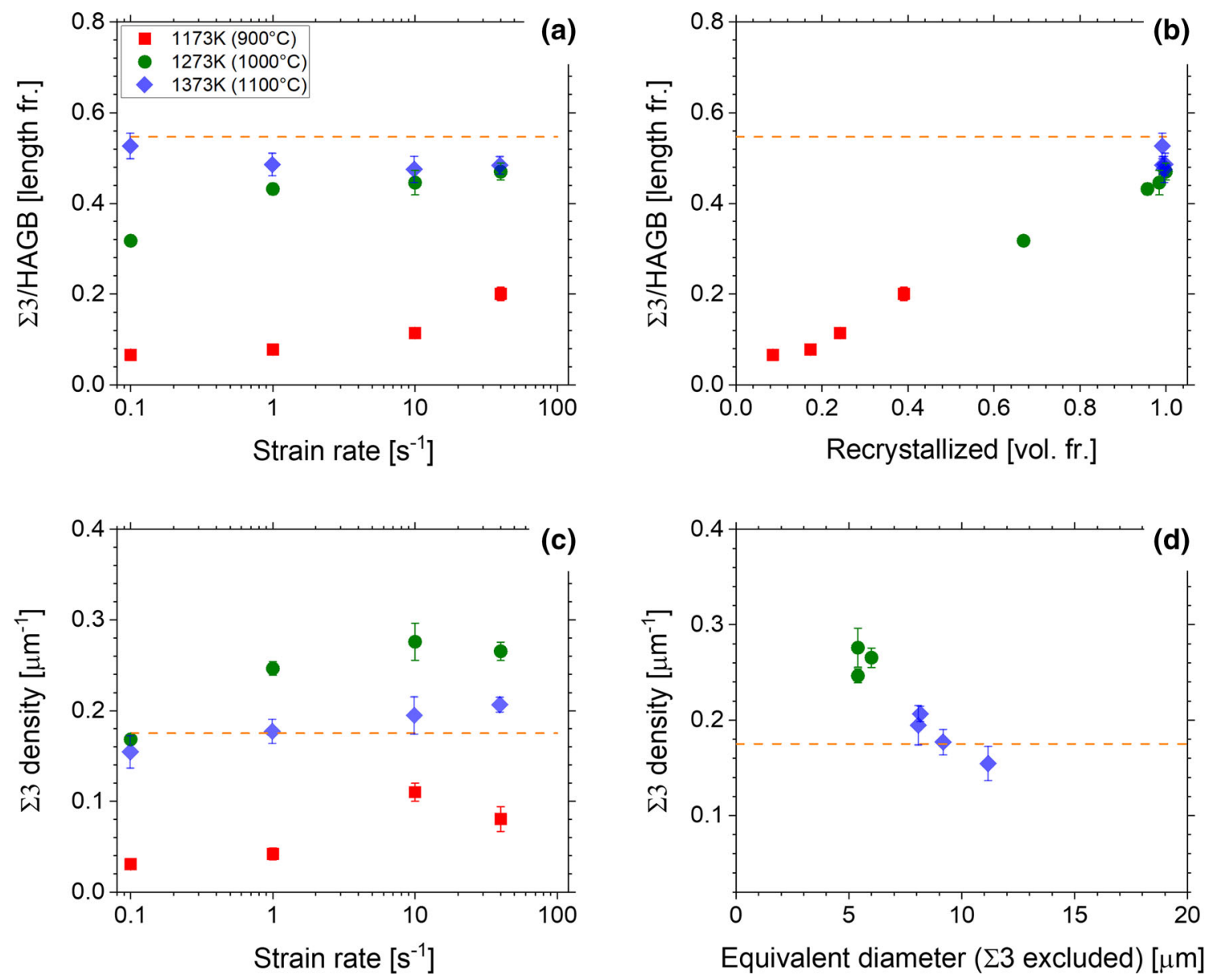

Fig. 9-Length fraction of $\Sigma 3$ boundaries as a function of $(a)$ deformation temperature and strain rate and $(b)$ recrystallized volume fraction, density of $\Sigma 3$ boundaries as a function of $(c)$ deformation temperature and strain rate and $(d)$ equivalent grain diameter for fully recrystallized samples (broken lines indicate initial microstructure, error bars denote one standard deviation based on the quadrant analysis).

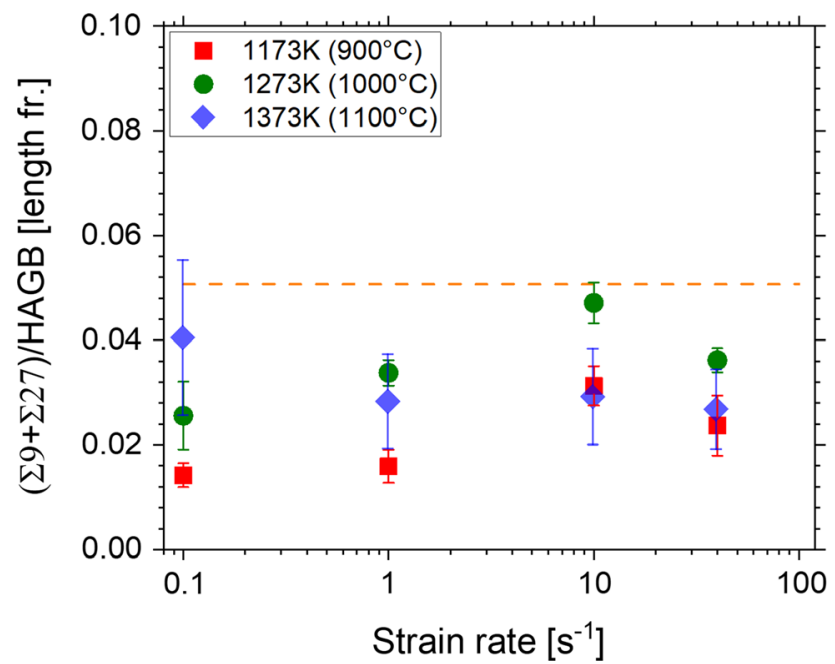

Fig. 10- Length fraction of $\Sigma 9$ and $\Sigma 27$ boundaries as a function of deformation temperature and strain rate (broken lines indicate initial microstructure, error bars denote one standard deviation based on the quadrant analysis).
Low-angle grain boundaries formed in unrecrystallized grains due to recovery. Although an experimentally measured value is not available, a stacking fault energy estimate at room temperature based on the empirical expression obtained for several austenitic stainless steels and taking into account the effect of nickel, chromium, magnesium, and molybdenum yields a value of $69 \mathrm{~mJ} \mathrm{~m}^{-2} \cdot{ }^{[28,29]}$ The stacking fault energy is expected to be higher for the range of deformation temperatures employed in this study; however, the consideration of nitrogen would have an opposite effect on the stacking fault energy estimate. Therefore, during and after hot deformation of a REX734 alloy having an intermediate level of stacking fault energy, the stored energy is reduced through both recovery and recrystallization. ${ }^{[29]}$

Slip transfer across interfaces is a complex process which depends on multiple factors including but not limited to properties of the boundary, the type of the dislocation, the orientation of slip systems in the adjacent grains, etc. ${ }^{[30]}$ As a result of the interaction between dislocations and grain boundaries, lattice dislocations can be either partially or fully incorporated 

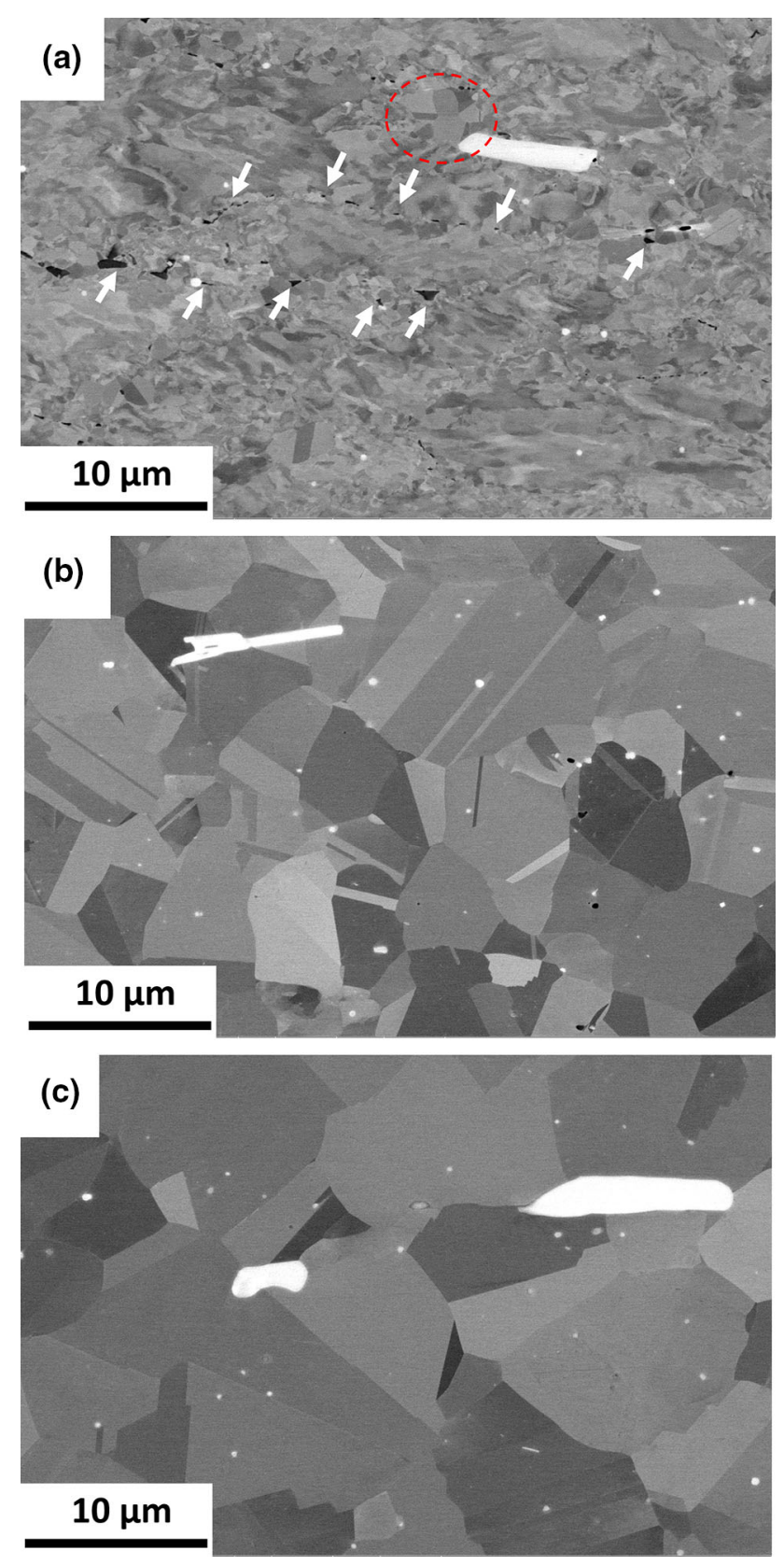

Fig. 11-Backscattered electron image after compression testing using the following combinations of temperature and strain rate: $(a)$ $1173 \mathrm{~K}\left(900{ }^{\circ} \mathrm{C}\right)$ to $1 \mathrm{~s}^{-1},(b) 1273 \mathrm{~K}\left(1000{ }^{\circ} \mathrm{C}\right)$ to $1 \mathrm{~s}^{-1},(c) 1373 \mathrm{~K}$ $\left(1100{ }^{\circ} \mathrm{C}\right.$ ) to $1 \mathrm{~s}^{-1}$ (arrows in (a) indicate chromium nitride precipitates delineating grain boundaries of unrecrystallized grain, circle in (a) highlights several recrystallized grains adjacent to a large Z-phase precipitate).

into the grain boundary, thereby changing its character. During hot deformation of a REX734 alloy, $\Sigma 3$ twin boundaries lose their twin character and transform into general high-angle grain boundaries. Similar observations have been reported for other alloys. ${ }^{[1,32]}$ As high-angle grain boundaries move to reduce the overall stored energy during recrystallization, new annealing twin boundaries form on migrating $\{111\}$ planes and are left behind in recrystallized grains. ${ }^{[33]}$ The frequency of annealing twins after thermomechanical processing

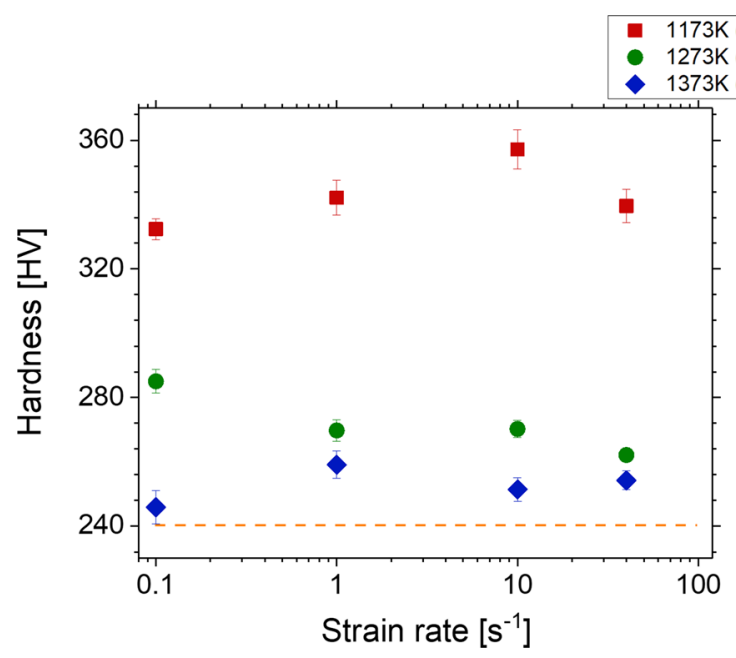

Fig. 12-Effect of deformation temperature and strain rate on hardness (broken lines indicate initial microstructure, error bars denote one standard deviation).

increases with the energy stored due to deformation. ${ }^{[34-36]}$ A higher stored energy available after deformation at $1273 \mathrm{~K}\left(1000{ }^{\circ} \mathrm{C}\right)$ is responsible for a smaller recrystallized grain size and a higher density of annealing twin boundaries compared to those after $1373 \mathrm{~K}$ $\left(1100{ }^{\circ} \mathrm{C}\right)$ deformation.

The morphology of coarse Z-phase precipitates was not altered as a result of deformation either; they are likely not to deform with the surrounding matrix. Orientation gradients are formed around large non-deformable particles due to strain incompatibility which leads to particle-stimulated nucleation. ${ }^{[3]}$ This mechanism assisted the recrystallization process in the present study. Recrystallized grains marked with a red circle and adjacent to about $10 \mu \mathrm{m}$-long Z-phase precipitate can be seen in Figure 11(a). On the contrary, fine Z-phase precipitates are expected to pin grain boundaries of recrystallizing grains thereby slowing down the recrystallization process. The variation in the content of chromium nitride precipitates with deformation temperature leads to a different level of pinning pressure on grain boundaries. A higher fraction of chromium nitride precipitates at $900{ }^{\circ} \mathrm{C}$ inhibits recrystallization; while during/after deformation at $1100^{\circ} \mathrm{C}$, where all chromium nitride precipitates dissolve, grain boundaries have fewer obstacles to overcome in the course of recrystallization.

\section{CONCLUSIONS}

The following conclusions can be drawn from the present study:

1. Both dynamic and post-dynamic restoration processes contribute to the formation of the final microstructure after compression testing; the latter takes place during the quench delay.

2. Deformation at $1173 \mathrm{~K}\left(900{ }^{\circ} \mathrm{C}\right)$ leads to a partially recrystallized microstructure, while fully recrystallized samples are obtained after deformation at 
$1273 \mathrm{~K}\left(1000{ }^{\circ} \mathrm{C}\right)$ (except for the slowest strain rate of $\left.0.1 \mathrm{~s}^{-1}\right)$ and $1373 \mathrm{~K}\left(1100{ }^{\circ} \mathrm{C}\right)$.

3. The high population of $\Sigma 3$ annealing twin boundaries originally present in the starting microstructure is transformed into general high-angle grain boundaries in the course of deformation. As a result, in partially recrystallized samples, unrecrystallized regions contain only low- and general high-angle grain boundaries. New $\Sigma 3$ boundaries form in the course of recrystallization.

4. The length fraction of $\Sigma 3$ annealing twin boundaries reaches the pre-deformation level of about 50 pct of the total length of all high-angle grain boundaries in fully recrystallized samples irrespective of deformation temperature and strain rate; while the final density of $\Sigma 3$ annealing twin boundaries increases with strain rate and decreases with temperature.

5. Based on the qualitative analysis of precipitates, Z-phase and chromium nitrides are found in the starting microstructure; the size and morphology of Z-phase precipitates does not appear to have been affected by compression testing, while the amount of chromium nitrides decreases with deformation temperature, completely disappearing after deformation at $1373 \mathrm{~K}\left(1100{ }^{\circ} \mathrm{C}\right)$.

\section{ACKNOWLEDGMENTS}

The authors would like to acknowledge the financial support for this project received through High Value Manufacturing CATAPULT (AFRC_CATP791 project). The authors would also like to thank Fraser Mateer, Kornelia Kondziolka and Ryan O'Neill for their assistance with machining compression samples, metallographic sample preparation, and collecting EBSD maps.

\section{OPEN ACCESS}

This article is distributed under the terms of the Creative Commons Attribution 4.0 International License (http://creativecommons.org/licenses/by/4.0/), which permits unrestricted use, distribution, and reproduction in any medium, provided you give appropriate credit to the original author(s) and the source, provide a link to the Creative Commons license, and indicate if changes were made.

\section{REFERENCES}

1. ASTM International: in Stainless Steels for Medical and Surgical Applications, G.L. Winters and M.J. Nutt, ed., vol. STP1438-EB, ASTM International, West Conshohocken, PA, 2003.

2. R.M. Pilliar: Biomedical Materials, Springer, Boston, 2009.

3. P.J. Yates, N.A. Quraishi, A. Kop, D.W. Howie, C. Marx, and E. Swarts: J. Arthroplasty, 2008, vol. 23 (2), pp. 188-96.
4. B.J.R.F. Bolland, M.J. Wilson, J.R. Howell, M.J.W. Hubble, A.J. Timperley, and G.A. Gie: J. Arthroplasty, 2017, vol. 32 (4), pp. 1318-22.

5. E. Swarts, A. Kop, N. Jones, C. Keogh, S. Miller, and P. Yates: $J$. Biomed. Mater. Res. A, 2008, vol. 84A (3), pp. 753-60.

6. K. Garala, T. Laios, and T. Lawrence: HIP Int., 2018, vol. 28 (6), pp. NP1-NP5.

7. R.A. Antunes and M.C.L. de Oliveira: Acta Biomater., 2012, vol. 8 (3), pp. 937-62.

8. E.J. Giordani, V.A. Guimarães, T.B. Pinto, and I. Ferreira: Int. J. Fatigue, 2004, vol. 26 (10), pp. 1129-36.

9. M.D. Sangid: Int. J. Fatigue, 2013, vol. 57, pp. 58-72.

10. M.D. Roach and S.I. Wright: Mater. Sci. Eng. A, 2014, vol. 607, pp. 611-20.

11. E.S. Silva, R.C. Sousa, A.M. Jorge, and O. Balancin: Mater. Sci. Eng. A, 2012, vol. 543, pp. 69-75.

12. R.C. Souza, E.S. Silva, A.M. Jorge, J.M. Cabrera, and O. Balancin: Mater. Sci. Eng. A, 2013, vol. 582, pp. 96-107.

13. F.R. Bernardes, S.F. Rodrigues, E.S. Silva, G.S. Reis, M.B.R. Silva, A.M.J. Junior, and O. Balancin: Mater. Sci. Eng. C, 2015, vol. 51, pp. 87-98.

14. D.H. Jack and K.H. Jack: J. Iron Steel Inst., 1972, vol. 210 (10), pp. 790-92.

15. M.B.R. Silva, J. Gallego, J.M. Cabrera, O. Balancin, and A.M. Jorge: Mater. Sci. Eng. A, 2015, vol. 637, pp. 189-200.

16. M.B.D.R. Silva, J.M. Cabrera, O. Balancin, and A.M. Jorge: Mater. Charact., 2017, vol. 127, pp. 153-60.

17. P.W. Robinson and D.H. Jack: J. Heat Treat., 1985, vol. 4 (1), pp. 69-74.

18. M. Ntovas and P. Blackwell: AIP Conf. Proc., 2017, vol. 1896 (1), p. 190002.

19. S. Zaefferer: Ultramicroscopy, 2007, vol. 107 (2), pp. 254-66.

20. F. Bachmann, R. Hielscher, and H. Schaeben: Ultramicroscopy, 2011, vol. 111 (12), pp. 1720-33.

21. S.I. Wright, M.M. Nowell, and D.P. Field: Microsc. Microanal., 2011, vol. 17 (3), pp. 316-29.

22. D.G. Brandon: Acta Metall., 1966, vol. 14 (11), pp. 1479-84.

23. N. Souaï, N. Bozzolo, L. Nazé, Y. Chastel, and R. Logé: Scr. Mater., 2010, vol. 62 (11), pp. 851-54.

24. P.O. Cubillos, C.T. dos Santos, I.M.V. Caminha, M. de Jesus Monteiro, R. de Oliveira Centeno, V.O. dos Santos, and C.R. de Mello Roesler: Metallogr. Microstruct. Anal., 2017, vol. 6 (1), pp. 44-54.

25. T. Sakai, A. Belyakov, R. Kaibyshev, H. Miura, and J.J. Jonas: Prog. Mater. Sci., 2014, vol. 60, pp. 130-207.

26. K. Huang and R.E. Logé: Mater. Des., 2016, vol. 111, pp. 548-74.

27. C. Roucoules, M. Pietrzyk, and P.D. Hodgson: Mater. Sci. Eng. A, 2003, vol. 339 (1), pp. 1-9.

28. R.E. Schramm and R.P. Reed: Metall. Trans. A, 1975, vol. 6 (7), p. 1345.

29. E.J. Giordani, A.M. Jorge, and O. Balancin: Scr. Mater., 2006, vol. 55 (8), pp. 743-46.

30. J. Kacher, B.P. Eftink, B. Cui, and I.M. Robertson: Curr. Opin. Solid State Mater. Sci., 2014, vol. 18 (4), pp. 227-43.

31. D. Ponge and G. Gottstein: Acta Mater., 1998, vol. 46 (1), pp. 69-80.

32. H. Beladi, P. Cizek, and P.D. Hodgson: Metall. Mater. Trans. A, 2009, vol. 40A (5), pp. 1175-89.

33. B. Lin: PhD thesis, Carnegie Mellon University, 2015, pp. 57-71.

34. M. Detrois, R.L. Goetz, R.C. Helmink, and S. Tin: Mater. Sci. Eng. A, 2015, vol. 647, pp. 157-62.

35. W. Wang, F. Brisset, A.L. Helbert, D. Solas, I. Drouelle, M.H. Mathon, and T. Baudin: Mater. Sci. Eng. A, 2014, vol. 589, pp. $112-18$.

36. Y. Jin, B. Lin, A.D. Rollett, G.S. Rohrer, M. Bernacki, and N. Bozzolo: J. Mater. Sci., 2015, vol. 50 (15), pp. 5191-5203.

37. J. Humphreys, G.S. Rohrer, and A. Rollett: in Recrystallization and Related Annealing Phenomena, Elsevier, Oxford, 2017, pp. $321-59$.

Publisher's Note Springer Nature remains neutral with regard to jurisdictional claims in published maps and institutional affiliations. 